\title{
Minding the Gap: Organizational Strategies to Promote Gender Equity in Academic Medicine During the COVID-19 Pandemic
}

\author{
Sirisha Narayana, $M D^{7}$ (D) Brita Roy, $M D, M P H, M H S^{2,3}$, Sarah Merriam, $M D, M S^{4,5}$, \\ Emmanuelle Yecies, MD, MS ${ }^{4,5}$, Rita S. Lee, MD' , Julie L. Mitchell, MD, MS', and \\ Amy S. Gottlieb, MD', on behalf of the Society of General Internal Medicine's Women \\ and Medicine Commission
}

\begin{abstract}
'Division of Hospital Medicine, Department of Medicine, University of California, San Francisco, CA, USA; '2Section of General Internal Medicine, Department of Medicine, Yale School of Medicine, New Haven, CT, USA; ${ }^{3}$ Department of Chronic Disease Epidemiology, Yale School of Public Health, New Haven, CT, USA; ${ }^{4}$ Division of General Internal Medicine, Department of Medicine, University of Pittsburgh School of Medicine, Pittsburgh, PA, USA; 5 Department of Medicine, VA Pittsburgh Healthcare System, Pittsburgh, PA, USA; ${ }^{6}$ Division of General Internal Medicine, Department of Medicine, University of Colorado School of Medicine, Aurora, CO, USA; ${ }^{7}$ Medical College of Wisconsin, Milwaukee, WI, USA; ${ }^{8}$ Office of Faculty Affairs, University of Massachusetts Medical School-Baystate, Springfield, MA, USA.
\end{abstract}

$\mathrm{J}$ Gen Intern Med 35(12):3681-4

DOI: $10.1007 / \mathrm{s} 11606-020-06269-0$

(C) Society of General Internal Medicine 2020

$\mathrm{T}$ he COVID-19 pandemic and its sequelae are likely to have disproportionate impact on women physicians, professionally and personally, and we must take steps to mitigate this undue burden. Women are more likely to be essential workers during the pandemic and comprise the majority of the healthcare workforce writ large. ${ }^{1}$ Compared with male colleagues, women in medicine also have increased responsibility for dependent care and domestic duties. ${ }^{2-7}$ In light of these additional roles and responsibilities, we are particularly concerned about women's sustained productivity, career advancement, and compensation as well as potentially deleterious effects on their well-being and retention. ${ }^{8}$ As we move into the next phase of the pandemic, whether it be recovery or planning for a resurgence, it is imperative that healthcare institutions pay attention to the inequitable impact policies and practices may have on a significant portion of our physician workforce. Furthermore, it is critical that decisions made during the current public health crisis do not erode previous progress our profession has made toward gender equity. In this statement, we highlight four crucial concerns and recommend organizational strategies to prevent or mitigate each.

1) Compensation and professional effort: In the United States, women physicians earn 75 cents on the dollar compared with their male counterparts, even after accounting for numerous potential confounders. ${ }^{9}$ In fact,

Received June 3, 2020

Accepted September 24, 2020

Published online October 6, 2020 physicians experience one of the largest gender pay gaps in the country. ${ }^{10,11}$ In the setting of financial hardship stemming from the COVID-19 pandemic, healthcare institutions will likely be scrutinizing the cost of employee compensation and reducing payroll expenditures where possible. ${ }^{12}$ Given pre-existing salary disparities, we strongly encourage organizational vigilance to ensure women physicians are not disproportionately penalized during cost-cutting initiatives. Moreover, we recommend leaders approach compensation and professional effort reviews that result from budgetary "tightening" exercises as opportunities to identify and implement practices to narrow existing gender gaps. At a minimum, to ensure that adjustments deemed necessary for fiscal viability do not exacerbate gender disparities, we recommend the following to institutional leaders and their finance, compensation, and operations teams:

- Standardize how professional effort is calculated among the three mission areas of education, research, and clinical care. Identify appropriate compensation benchmarks for this effort and apply these metrics consistently across departments and divisions. Conduct salary audits and, when doing so, consider base pay, incentive pay, and leadership stipends with an eye toward equity and eligibility. Women in medicine experience well-documented disparities in leadership opportunities, ${ }^{13,14}$ potentially limiting their earning potential. Because women are also disproportionately assigned to uncompensated service-related tasks within organizations (e.g., committee work), salary studies should attempt to capture professional effort related to non-clinical activities. ${ }^{15-17}$

- Robustly monitor gender metrics pertaining to fulltime equivalent (FTE) reductions and/or reallocations and assess impact on total compensation (salary and 
benefits) - at many institutions, reduction in FTE leads to a disproportionate decrease in benefits like healthcare coverage. Commit to sharing these metrics throughout the institution in a transparent and accessible manner, and preferably provide forums for discussion and feedback prior to implementation.

- Identify and account for reduced year-end clinical productivity and reimbursement due to COVID-19 so as not to impact incentive compensation negatively.

- Ensure that women physicians participate in organizational decision-making around changes to salary, benefits, and professional effort due to the pandemic. Incorporating women's voices, knowledge, and leadership in this arena is critical to developing equitable (and realistic) practices.

- In the setting of pay freezes or salary reductions in response to the pandemic, reimburse individuals for monies that would have been earned, when institutional finances allow, with a focus on achieving pay equity.

- Consider awarding stipends to physicians who are redeployed to COVID-19-related work.

2) Family support: Emerging evidence suggests that more women than men are shouldering the burden of the pandemic's effect on domestic life. ${ }^{8} 18$ Prior to the COVID-19 pandemic, research demonstrated that childcare disruptions fall disproportionately on women physicians, who report having to take time away from work to care for children significantly more frequently than male peers $(42.6 \%$ v. $12.4 \%){ }^{2}$ Current public health mandates, such as school and daycare closures and shelter-in-place ordinances, likely exacerbate this imbalance between male and female physicians, impacting clinical activities, grant application submissions, manuscript preparation, and teaching. ${ }^{19-24}$ In order to minimize potential adverse effects on productivity, advancement, and promotion, we recommend institutional leaders and their operations, human resources, and faculty affairs teams do the following:

- Continue alternate (and flexible) work schedules as well as enhanced access for remote working during non-surge periods.

- Partner with local businesses to offer subsidized or bulk discounts to support self- and family-care needs such as dry cleaning, food delivery, and housecleaning, to minimize the financial and time burdens of these activities.

- Promote efforts within departments or divisions to pool and vet dependent care providers for all to share (if not already established by the institution).

- Collaborate with local organizations, including existing childcare providers, to create or reopen care centers for children of essential workers.
- Consider introducing or increasing subsidies for dependent care costs if school or daycare closures cause undue financial hardship.

- Develop social support hubs and practical seminars focused on resiliency, managing vicarious trauma, and building camaraderie and community. Be mindful that these opportunities do not place additional burden on women physicians to organize and execute.

3) Academic productivity: Gender disparities that impact women's advancement in academic medicine have been well-described. ${ }^{13,25}$ In particular, women faculty have had lower rates of peer-reviewed publications and grant funding from the National Institutes of Health. ${ }^{26-31}$ In the current pandemic, preliminary communications show a stark decrease in submissions to scientific journals by women investigators ${ }^{32,} 33$ as well as fewer first-author COVID-19 publications compared with men. ${ }^{20-24}$ Additionally, educators have had to accommodate rapid changes in curricula and adapt teaching techniques for remote learning, which may impede or supersede other scholarly and educational endeavors. To combat these barriers to academic productivity, we recommend institutional leaders, including offices of faculty affairs and research, do the following:

- Implement a mechanism to capture "COVID-19 contributions" on curriculum vitae and specifically encourage women faculty to document their efforts. The pandemic has afforded unique opportunities for innovation in operations, clinical care, research, and teaching. Contributions may include developing evidence-based institutional guidelines, creating patient-centered communications, responding to media or other inquiries, building forums for peer education or community-building, attending to trainee education, and analyzing social determinants of health and inequities.

- Encourage the inclusion of women on COVID-19 research teams, and sponsor women for dedicated institutional and national COVID-19 research funding opportunities.

- Allow scholarly activities (e.g., invited talks, conference workshops) that were canceled or had to be declined because of the COVID-19 pandemic to be listed on curriculum vitae.

- Ensure that women and those with diverse research portfolios are included in decision-making around prioritizing activities within the research enterprise.

- Resist cuts to internal grant mechanisms that support early career investigators.

- Consider the long-term implications on career advancement before implementing cost-cutting measures that would diminish travel time and funding for scholarly endeavors (e.g., reducing annual allotments 
for conference attendance and prohibiting professional travel).

- Develop promotion structures and processes to recognize COVID-19 research, clinical care, administration, and teaching.

- Develop a mechanism for extending promotion deadlines for academic faculty to account for disruptions in productivity and opportunities related to the COVID-19 pandemic. Normalize this extension by creating a culture of acceptance around productivity challenges during the pandemic or by automating a standard extension for all faculty.

4) Career development: Networking, sponsorship, and leadership development are critical to advancing women in academic medicine. Women's professional networks are less extensive than their male colleagues. ${ }^{34,} 35$ Further, women face greater barriers to career mentorship, sponsorship, and obtaining protected time for scholarship, and are more likely to experience burnout than their male colleagues. ${ }^{36,} 37$ Diminished travel funding, reduced time for conference attendance because of personal responsibilities and institutional cost-cutting measures, and cancelation of professional development activities due to social distancing policies may have a long-term impact on women's careers. We urge institutions to protect investment in opportunities that support women's advancement, including programs that help identify sponsors, mentors, and collaborators. More immediately, we recommend institutional leaders, including department chairs, division chiefs, and faculty affairs deans commit to the following:

- Capitalize on affiliations with national organizations such as the Society of General Internal Medicine (SGIM) and the American Association of Medical Colleges (AAMC) that have professional development and sponsorship programs that specifically benefit women physicians and allow for remote participation (e.g., SGIM's Career Advising Program). ${ }^{38}$

- When possible, maintain funding streams for institutional programs that support women's career advancement and leadership development.

- Widely publicize organizational leadership opportunities and ensure that women have strong representation on search and promotion committees.

The COVID-19 pandemic has highlighted inequities among patients and providers alike. As we enter each new phase of this devastating public health crisis, we must not lose the gains we as a profession have made toward reducing gender disparities among our physician workforce. In fact, we could take this unprecedented opportunity to improve policies and practices with an eye toward equity. Organizations should be encouraged to pay attention to decision-making where disparities could emerge and adopt strategies like those outlined above.

Acknowledgments: We thank providers of all genders, and gender non-conforming, who have sustained and cared for our nation during this pandemic.

Corresponding Author: Sirisha Narayana, MD; Division of Hospital Medicine, Department of Medicine, University of California, San Francisco, CA, USA (e-mail: sirisha.narayana@ucsf.edu).

\section{Compliance with ethical standards:}

Conflict of Interest: The authors disclose no conflicts of interests, financial or otherwise.

\section{REFERENCES}

1. Robertson C, Gebeloff $\mathbf{R}$. How millions of women became the most essential workers in America. The New York Times. Published April 18, 2020. Available at: https://www.nytimes.com/2020/04/18/us/ coronavirus-women-essential-workers.html. Accessed 21 May 2020.

2. Jolly S, Griffith KA, DeCastro R, Stewart A, Ubel P, Jagsi R. Gender differences in time spent on parenting and domestic responsibilities by high-achieving young physician-researchers. Ann Intern Med 2014; 160(5): 344-353.

3. Sobecks NW, Justice AC, Hinze S, et al. When doctors marry doctors: a survey exploring the professional and family lives of young physicians. Ann Intern Med 1999;130(4 Pt 1): 312-319.

4. Lyu HG, Davids JS, Scully RE, Melnitchouk N. Association of domestic responsibilities with career satisfaction for physician mothers in procedural vs non-procedural fields. JAMA Surg 2019;154(8):689-695.

5. Ly DP, Seabury SA, Jena AB. Characteristics of US physician marriages, 2000-2015: an analysis of data from a US census survey. Ann Intern Med 2018;168(5): 375-376.

6. Potee RA, Gerber AJ, Ickovics JR. Medicine and motherhood: shifting trends among female physicians from 1922 to 1999. Obstet Gynecol Surv 2000; 55(3): 144-145.

7. Unpaid Eldercare in the United States - 2017-2018: Data from the American time use survey. U.S. Bureau of Labor Statistics: Department of Labor. 2019. Available at: https://www.bls.gov/news.release/pdf/ elcare.pdf. Accessed 15 March 2020.

8. Frederiksen B, Gomez I, Salganicoff A, Ranji U. Coronavirus: A look at gender differences in awareness and actions. Kaiser Family Foundation. Published Mar 20, 2020. Available at: https://www.kff.org/womenshealth-policy/issue-brief/coronavirus-a-look-at-gender-differences-inawareness-and-actions

9. Doximity 2019 Physician Compensation Report. San Francisco: March 2019. Available from: https://s3.amazonaws.com/s3.doximity. com/press/doximity_third_annual_physician_compensation_report_ round4.pdf. Accessed 20 May 2020.

10. Women's Bureau, US Department of Labor. Earnings and Ratios: Gender earnings ratio by weekly earnings. Washington, DC: US Department of Labor; 2020. Available from: https://www.dol.gov/agencies/wb/data/ facts-over-time/earnings-and-earnings-ratios\# gender-earnings-ratio-byweekly-earnings. Accessed 20 May 2020.

11. Women's Bureau, US Department of Labor. Earnings: Occupations with the largest gender earnings gap. Washington, DC: US Department of Labor; 2020. Available from: https://www.dol.gov/agencies/wb/data/ earnings\#earnings-ratio. Accessed 20 May 2020.

12. Cutler DM, Nikpay S, Huckman RS. The Business of Medicine in the Era of COVID-19. JAMA. 2020;323(20):2003-2004

13. Raj A, Kumra T, Darmstadt GL, Freund KM. Achieving gender and social equality: More than gender parity is needed. Acad Med 2019:94(11);1658-1664.

14. Jena AB, Khullar D, Ho O, Olenski AR, Blumenthal DM. Sex differences in academic rank in US medical schools in 2014. JAMA. 2015;314(11):1149-1158.

15. Babcock $\mathbf{L}$, Recalde MP, Vesterlund $\mathbf{L}$. Why women volunteer for tasks that don't lead to promotions. Harvard Business Review. Published July 16, 2018. Available from: https://hbr.org/2018/07/why-women- 
volunteer-for-tasks-that-dont-lead-to-promotions. Accessed 20 May 2020.

16. Mitchell SM, Hesli VL. Women don't ask? Women don't say no? Bargaining and service in the political science profession. Polit Sci Polit 2013;46(2):355-369

17. Misra J, Lundquist JH, Templer A. Gender, work time, and care responsibilities among faculty. Sociol Forum, 2012; 27(2): 300-323.

18. Shaw E, Mason CN, Lacarte V, Jauregui E. Holding up half the sky: mothers as workers, primary caregivers, \& breadwinners during COVID19. Institute for Women's Policy Research. Published May 8, 2020. Available at: https://iwpr.org/wp-content/uploads/2020/07/HoldingUp-Half-the-Sky-Mothers-as-Breadwinners.pdf. Accessed 17 May 2020.

19. Waisbren SE, Bowles H, Hasan T, et al. Gender differences in research grant applications and funding outcomes for medical school faculty. J Women's Health 2008;17(2): 207-214.

20. Andersen JP, Nielsen MW, Simone NL, Lewiss RE, Jassi R. MetaResearch: COVID-19 medical papers have fewer women first authors than expected. eLife 2020; 9: e58807.

21. Vincent-Lamarre $\mathbf{P}$, Sugimoto $\mathbf{C R}$, Lariviere $\mathbf{V}$. The decline of women's research production during the coronavirus pandemic. Nat. Index. May 19, 2020. Available at: https://www.natureindex.com/news-blog/ decline-women-scientist-research-publishing-production-coronaviruspandemic. Accessed 17 Aug 2020

22. Gabster BP, van Daalen K, Dhatt R, Barry M. Challenges for the female academic during the COVID-19 pandemic. Lancet. 2020; 395:19681970.

23. Frederickson M, COVID-19's gendered impact on academic productivity. May 11, 2020. Available at: https://github.com/drfreder/pandemic-pubbias. Accessed 17 Aug 2020.

24. Amano-Patiño N, Faraglia E, Giannitsarou C, Hasna Z. Who is doing new research in the time of COVID-19? Not the female economists. Vox EU. May 2, 2020. Available at: https://voxeu.org/article/who-doing-newresearch-time-covid-19-not-female-economists. Accessed 17 Aug 2020.

25. Butkus R, Serchen J, Moyer DV, Bornstein SS, Hingle ST. Achieving gender equity in physician compensation and career advancement: a position paper from the American College of Physicians. Ann Intern Med 2018;168(10):721-723.

26. Jagsi R, Guancial EA, Worobey CC, Henault LE, Chang Y, Starr R. The "gender gap" in authorship of academic medical literature-a 35-year perspective. N Engl J Med 2006; 355(3): 281-287.

27. Jagsi R, Motomura AR, Amarnath S, Jankovic A, Sheets N, Ubel PA Under-representation of women in high-impact published clinical cancer research. Cancer. 2009;115(14):3293-3301.
28. Reed DA, Enders F, Lindor $\mathbf{R}$, McClees $\mathbf{M}$, Lindor $\mathbf{K D}$. Gender differences in academic productivity and leadership appointments of physicians throughout academic careers. Acad Med 2011;86(1): 43-47.

29. Filardo G, da Graca B, Sass DM, Pollock BD, Smith EB, Martinez MAM. Trends and comparison of female first authorship in high impact medical journals: observational study (1994-2014). BMJ. 2016; 352: i847.

30. Kaatz A, Lee YG, Potvien A, et al. Analysis of National Institutes of Health R01 application critiques, impact, and criteria scores: does the sex of the principal investigator make a difference? Acad Med 2016;91(8): 1080-1088

31. Raj A, Carr PL, Kaplan SE, Terrin N, Breeze JL, Freund KM. Longitudinal analysis of gender differences in academic productivity among medical faculty across 24 medical schools in the United States. Acad Med 2016;91(8):1074-1079.

32. Kitchener C. Women academics seem to be submitting few papers during coronavirus. 'Never seen anything like it' says one editor. The Lily by the Washington Post. Published April 24, 2020. Available at: https://www.thelily.com/women-academics-seem-to-be-submittingfewer-papers-during-coronavirus-never-seen-anything-like-it-saysone-editor/. Accessed 17 May 2020.

33. Viglione G. Are women publishing less during the pandemic? Here's what the data say. Nature. 2020; 581: 365-366.

34. Hitchcock M, Bland CJ, Hekelman FP, Blumenthal MG. Professional networks: the influence of colleagues on the academic success of faculty. Acad Med1995; 70(12):1108-16.

35. Uzzi B. Men and women need different kinds of networks to succeed. Harvard Business Review. Published Feb 25, 2019. Available at: https:// hbr.org/2019/02/research-men-and-women-need-different-kinds-ofnetworks-to-succeed. Accessed 21 May 2020.

36. McMurray JE, Linzer M, Konrad TR, Douglas J, Shugerman R, Nelson $\mathbf{K}$. The work lives of women physicians: results from the physician worklife study. J Gen Intern Med 2000;15(6):372-80.

37. Limacher M, Zaher CA, Walsh MN, et al. The ACC professional life survey: career decisions of women and men in cardiology. J Am Coll Cardiol 1998;32(3):827-35.

38. Bates CK and Gottlieb AS. Moving the Needle on Gender Equity: a Call for Personal and Organizational Action. J Gen Intern Med 2019;34(3):329-330.

Publisher's Note: Springer Nature remains neutral with regard to jurisdictional claims in published maps and institutional affiliations. 